\title{
BIOLOGY OF THE ANGOUMOIS GRAIN MOTH, SITOTROGA CEREALELLA (Oliver) ON STORED RICE GRAIN IN LABORATORY CONDITION
}

\author{
T. AKTER, M. JAHAN ${ }^{1}$ AND M.S. I. BHUIYAN \\ Department of Entomology, Sher-e-Bangla Agricultural \\ University, Dhaka-1207, Bangladesh \\ ${ }^{1}$ Department of Entomology, Bangladesh Agricultural University, \\ Mymensingh-2202, Bangladesh
}

\begin{abstract}
The experiment was conducted in the laboratory of the Department of Entomology, Shere-Bangla Agricultural University, Dhaka during the period from May 2009 to April 2010 to study the biology of the Angoumois grain moth, Sitotroga cerealella (Oliver) in Bangladesh. The ovipositional period, incubation period, larval period, pre-pupal period and pupal period of Angoumois grain moth were 3.67 days, 5.5 days, 25.2 days, 3.0 days and 5.0 days, respectively; male and female longevity of moth were 8.0 and10 days, respectively. The lengths of all five larval instars were $1.0 \pm 0.00,2.0 \pm 0.02,4.0 \pm 0.06$, $5.0 \pm 0.03$ and $4.0 \pm 0.06 \mathrm{~mm}$, and the widths were $0.10 \pm 0.0,0.4 \pm 0.0,0.6 \pm 0.01,0.8 \pm$ 0.02 and $1.0 \pm 0.09 \mathrm{~mm}$, respectively. The length and width of the pre-pupa and the pupa were $4.0 \pm 0.02,3.5 \pm 0.01 \mathrm{~mm}$ and $1.20 \pm 0.05,1.50 \pm 0.03 \mathrm{~mm}$ respectively. The length of male and female was $11.2 \pm 0.09$ and $12.07 \pm 0.06 \mathrm{~mm}$ respectively.
\end{abstract}

Key words: Biology, Angoumois grain moth, Sitotroga cerealella, Stored rice grain

\section{Introduction}

Angoumois grain moth, Sitotroga cerealella (Oliver) (Lepidoptera: Gelechiidae) is a primary colonizer of stored grain in subtropical and warm temperate regions of the world. Rice is the most important cereal crop and staple food in Bangladesh. The demand for rice is constantly rising in Bangladesh with nearly 2.3 million people being added each year to her population of about 120 million (Anon. 2001). About $90 \%$ of the population of Bangladesh depends on rice for their major food intake (Anon. 1981). The farmers store more than $65 \%$ of the total produced rice till the next season for their food, feed and seed purposes. Insect pests damage different types of stored grains including rice causing serious loss to national economy. Among them Angoumois grain moth is one of the most serious pests of stored rice (unhusked) at post harvest level. At the time of harvest the panicle shows no sign of infestation usually, and the first adults emerge some weeks later in storage. A large quantity of unhusked rice is stored at farmer's level which is badly damaged by $S$. cerealella, which is an extremely efficient seed penetrator (Cogburn 1975). Angoumois grain moth, S. cerealella also known as the rice moth or paddy moth is one of the most dominant species in the stored paddy (Prakash et al. 1984). In Bangladesh it is locally known as "surui poka". In the bag stored with the paddy, it appeared to be the major and number one pest. It not only infests the grains in storage, 
but also in field conditions, which enhances its ability to damage (Douglus 1941). The newly hatched caterpillar bores directly into the grain and typically remains inside the grain for both larval and pupal development. The larvae of this pest tunnel inside the kernels are causing substantial damage and are rendering the grain more susceptible to secondary insect pests (Weston and Rattlingourd 2000). Before pupation the larva constructs a chamber just under the grain seed coat, forming a small circular translucent window. Pupation takes places within the chamber inside a delicate cocoon. Adults fly well and cross-infestation occurs readily, but they are short-lived and generally survive only for 5-12 days, and in suitable stores breeding may be continuous throughout the year (Hill 1990).

\section{Materials and Methods}

The study was conducted in the laboratory of the Department of Entomology, Sher-eBangla Agricultural University, Dhaka during the period from May 2009 to April 2010. Parboiled rice variety BR-11, collected from farm store house of Sher-e-Bangla Agricultural University, was used for this investigation. Male and female adult moths were also collected from farm store house of the same University. Male and female adult moths were sorted out under a simple microscope by observing their abdominal tergites. In males, the abdomen is thinner, pointed and blackish when viewed from the ventral side whereas in females, the abdomen is bulky and long without any blackish coloration and size of the body (male is smaller than female). The comparative biology of Sitotroga cerealella was studied on rice grains in laboratory conditions by maintaining them at room temperature. The collected moths were enclosed in plastic jars (measuring $25 \times 30$ $\mathrm{cm}$ ) for mating and oviposition.

Collection of the eggs of S. cerealella: For the collection of fresh egg mass, the rearing of $S$. cerealella was done by using wheat grain (only for rearing purposes) as a diet in a special mass rearing chamber. From $S$. cerealella mass rearing chamber, thousands of adults were collected and kept them in a glass cylinder. The top of the cylinder was covered by 32 mesh net. Adults were kept in a cylinder for one day for mating and subsequent egg laying on the glass cylinder. In the consecutive days the eggs laid on the wall of the cylinder were brushed and sieved to collect fresh eggs along with body parts of moth. Then the body parts of moth were cleaned and fresh eggs were obtained. The collected eggs of $S$. cerealella were kept into a glass tube with labeling and stored in a refrigerator at $4^{0} \mathrm{C}$ temperature to ensure continuous supply for future study.

Biology of S. cerealella: The eggs of S. cerealella were laid on pieces of white paper placed on Petridish for hatching. The newly hatched larvae were transferred in Petri dishes with grains. The morphological characteristics of the larvae and pupae were studied and recorded during the period of larval and pupal development respectively. 
Different growth and development stages of $S$. cerealella, such as incubation period, larval period, pupal period and adult longevity were studied during the experimental period. The incubation period was assessed based on the time the egg was laid and the time the larva was emerged from a particular egg. Larval and pupal periods were recorded by cutting infested grains with the help of a blade and observed under the microscope. The emerging adults of $S$. cerealella were kept in the glass tube until death and the adult longevity was recorded.

Length and width: The length and width of different stages of the insect were observed under a sterio- microscope and measured with the help of slide calipers.

\section{Results and Discussion}

Mating and Oviposition: The Angoumois grain moth, $S$. cerealella adults used to start their mating after passing $24 \mathrm{hrs}$ of emergence. On rice grains, a single female moth laid eggs from 42 to 213 with an average of 109 eggs throughout its life (Table1). The eggs were laid singly or in groups of 4-7 depending upon the season and ovipositional site. Fletcher and Ghosh (1919) observed that a female laid 120-350 eggs on paddy grains and other cereals and also on depressions, cracks, crevices and holes of storage structures and godowns. Dhotmal and Dumbre (1982) reported that from 41 to 58 eggs were laid by a female on different rice varieties in a laboratory test and found that fine grain varieties were preferred for egg laying. On an average, oviposition period was found to be $3.67 \pm$ 0.01 days (Table 2 ). Newly hatched egg was white in color, but gradually changed to

Table 1. Number of eggs of Sitotroga cerealella laid at different days on rice grains in the laboratory condition (temperature $27^{\circ} \mathrm{C}$ and $70-72 \% \mathrm{RH}$ ).

\begin{tabular}{c|cccccc}
\hline \multirow{2}{*}{ Insect } & \multicolumn{5}{|c|}{ Number of eggs laid } & Total number of \\
\cline { 2 - 4 } & $1^{\text {st }}$ day & $2^{\text {nd }}$ day & $3^{\text {rd }}$ day & $4^{\text {th }}$ day & laid \\
\hline $1^{\text {st }}$ pair & 150 & 50 & 10 & 0 & 210 \\
$2^{\text {nd }}$ pair & 28 & 56 & 22 & 07 & 113 \\
$3^{\text {rd }}$ pair & 12 & 23 & 07 & 0 & 42 \\
$4^{\text {th }}$ pair & 34 & 37 & 22 & 02 & 96 \\
$5^{\text {th }}$ pair & 37 & 57 & 16 & 10 & 120 \\
$6^{\text {th }}$ pair & 30 & 28 & 15 & 06 & 79 \\
$7^{\text {th }}$ pair & 26 & 17 & 0 & 0 & 43 \\
$8^{\text {th }}$ pair & 37 & 23 & 08 & 0 & 68 \\
$9^{\text {th }}$ pair & 43 & 35 & 17 & 11 & 106 \\
$10^{\text {th }}$ pair & 143 & 57 & 10 & 03 & 213 \\
\hline
\end{tabular}


reddish brown with age. It measured about $0.5 \mathrm{~mm}$ in diameter. The egg was oval shaped and hatched within a week. An average incubation period was $5.5 \pm 0.03$ days (Table 2), but in summer season incubation period was from 2 to 3 days and in winter season it ranged from 5 to more (overall, incubation period depends on temperature and relative humidity). Hatching was reported to take 11 days at $17.3^{\circ} \mathrm{C}$ temperature and $68.3 \%$ R.H. (Germanov 1982). Unmated females have also been reported to lay eggs within a day of emergence (Ayertey 1975). Prakash et al. (1981) reported that for egg lying female prefers a rough surface than a smooth one in stored rice.

Table 2. Developmental period of different life stages of Sitotroga cerealella on rice grain in the laboratory.

\begin{tabular}{lcc}
\hline Development stage & Duration (days) & Statistics \\
\hline Oviposition & $3.67 \pm 0.01$ & $\mathrm{P}<0.002$ \\
Incubation & $5.5 \pm 0.03$ & $\mathrm{P}<0.004$ \\
Larval Period & & \\
$\quad 1^{\text {st }}$ Instar & $3.2 \pm 0.09$ & $\mathrm{P}<0.000$ \\
$\quad 2^{\text {nd }}$ Instar & $4.0 \pm 0.11$ & $\mathrm{P}<0.012$ \\
$\quad 3^{\text {rd }}$ Instar & $10.0 \pm 0.23$ & $\mathrm{P}<0.004$ \\
$\quad 4^{\text {th }}$ Instar & $6.0 \pm 0.07$ & $\mathrm{P}<0.031$ \\
$\quad 5^{\text {th }}$ Instar & $3.0 \pm 0.03$ & $\mathrm{P}<0.001$ \\
Pre-pupal & $3.0 \pm 0.05$ & $\mathrm{P}<0.098$ \\
Pupal & $5.0 \pm 0.08$ & $\mathrm{P}<0.019$ \\
Adult Longevity & & \\
$\quad$ Male & $8.0 \pm 0.13$ & $\mathrm{P}<0.000$ \\
$\quad$ Female & $10.0 \pm 0.32$ & $\mathrm{P}<0.005$ \\
\hline
\end{tabular}

Larval period: The larvae developed through five instars. The newly hatched larvae of all instars were yellowish white in colour with light brown head. The stadia of the $1^{\text {st }}, 2^{\text {nd }}$, $3^{\text {rd }}, 4^{\text {th }}$ and $5^{\text {th }}$ instar larvae were $3.2 \pm 0.09,4.0 \pm 0.11,10.0 \pm 0.23,6.0 \pm 0.07$ and $3.0 \pm$ 0.03 days, respectively (Table 2). The lengths of all five larval instars were $1.0 \pm 0.00$, $2.0 \pm 0.02,4.0 \pm 0.06,5.0 \pm 0.03$ and $4.0 \pm 0.06 \mathrm{~mm}$, respectively and the widths were $0.1 \pm 0.0,0.4 \pm 0.0,0.6 \pm 0.01,0.8 \pm 0.02$ and $1.0 \pm 0.09 \mathrm{~mm}$, respectively (Table 3).

The tiny larva lives inside a grain. It crawls around for sometimes and soon finds a comparatively weaker spot or a crack or split in the husk through which it enters the grain. Larval migration is reported as being up to $10 \mathrm{~cm}$ horizontally and $5 \mathrm{~cm}$ vertically (Germanov 1982). After entering the grain, the larva often turns and practically closes the entry hole with a silken web. The larval life then begins in an environment of plenty of food and safety and continues in that state till it is fully grown to about $5 \mathrm{~mm}$ within two 
or three weeks. At this time the grain is practically hollow filled with faeces and other refuge. The larva then cuts out a circular exit hole leaving over it just a sort of cap (Anon. 2001). Germanov (1982) described four larval stages during his studies under conditions of mass rearing and reported that larval stages I, II, III and IV were observed on the $9^{\text {th }}$, $12^{\text {th }}, 18^{\text {th }}$ and $20^{\text {th }}$ days respectively after grain infestation at $22.3^{\circ} \mathrm{C}$ temperature and $65.8 \%$ RH. Duration of larva was found to be from 13.66 to 19.33 days in different rice varieties and development was faster in fine-grained varieties (Dhotmal and Dumbre 1982). Full-grown larvae spin silken cocoons around them in hollows in the grain and become inactive for two days before pupation (Crombie 1943).

Table 3. Morphometirics of different life stages of Sitotroga cerealella on rice grain in the laboratory.

\begin{tabular}{l|c|c}
\hline \multirow{2}{*}{ Life Stage } & \multicolumn{2}{c}{ Size (mm) } \\
\cline { 2 - 3 } & $0.8 \pm 0.00$ & Wength \\
\hline Egg & & $0.5 \mathrm{~mm}$ in diameter \\
Larval Instars & $1.0 \pm 0.00$ & \\
$\quad 1^{\text {st }}$ Instar & $2.0 \pm 0.02$ & $0.10 \pm 0.00$ \\
$2^{\text {nd }}$ Instar & $4.0 \pm 0.07$ & $0.40 \pm 0.00$ \\
$3^{\text {rd }}$ Instar & $5.0 \pm 0.03$ & $0.60 \pm 0.01$ \\
$\quad 4^{\text {th }}$ Instar & $4.0 \pm 0.06$ & $0.80 \pm 0.02$ \\
$\quad 5^{\text {th }}$ Instar & $4.0 \pm 0.02$ & $1.00 \pm 0.09$ \\
Pre-pupa & $3.5 \pm 0.01$ & $1.20 \pm 0.05$ \\
Pupa & & $1.50 \pm 0.03$ \\
Adult wing span & $11.2 \pm 0.09$ & \\
$\quad$ Male & $12.7 \pm 0.06$ & \\
$\quad$ Female & & \\
\hline
\end{tabular}

Pupal period: Pupa is brown coloured, develops inside silken cocoon. Total $3.0 \pm 0.05$ days were required for pre-pupal stage and $5 \pm 0.08$ days for pupal stage under the laboratory condition (Table 2). The pre-pupa measured $4.0 \pm 0.02 \mathrm{~mm}$ in length and 1.20 $\pm 0.05 \mathrm{~mm}$ width and the pupa measured $3.5 \pm 0.01 \mathrm{~mm}$ in length and $1.50 \pm 0.03 \mathrm{~mm}$ width in rice grain (Table 3). Generally, pupal period is 4-7days (Crombie 1943). The moth, on emergence, pushes off the cap on the circular exit hole. Germanov (1982) reported pupation on the $15^{\text {th }}$ day after infestation at $22.3^{\circ} \mathrm{C}$ temperature and $68.8 \%$ relative humidity.

Adult Period: The adult was a good filter, gray or buff coloured moth, usually nocturnal in habit. The longevity of females was more than that of males. The adult longevity was 8 \pm 0.13 days for male and $10 \pm 0.32$ days for female (Table 2). The length of male was $11.2 \pm 0.09 \mathrm{~mm}$ and $12.07 \pm 0.06 \mathrm{~mm}$ for female in rice grain (Table 3). From Table 4, we observed that moth development stage duration also varied in different temperatures. The highest developmental period (25.05 days) of $S$. cerealella was found from the lowest temperature $20^{\circ} \mathrm{C}$ which was statistically different from other different temperatures and closely followed by the temperature $24^{\circ} \mathrm{C}$ (22.60 days). The lowest 
developmental period (17.42 days) of $S$. cerealella was found from $32^{\circ} \mathrm{C}$ temperature. With the increase of temperature moth development stage duration also decreased significantly (Table 4). According to Hill (1990), total larval development of S. cerealella

Table 4. Development of Sitotroga cerealella at different constant and cycling temperatures at $50-65 \%$ relative humidity.

\begin{tabular}{c|c|c}
\hline Temperature $\left({ }^{0} \mathrm{C}\right)$ & Number observed & $\begin{array}{c}\text { Mean developmental period } \\
(\text { Days } \pm \text { SE) }\end{array}$ \\
\hline 20 & 58 & $25.05 \pm 0.21^{\mathrm{a}}$ \\
24 & 68 & $22.60 \pm 0.21^{\mathrm{b}}$ \\
28 & 67 & $20.93 \pm 0.17^{\mathrm{c}}$ \\
32 & 55 & $17.42 \pm 0.23^{\mathrm{d}}$ \\
${ }^{*} 20 / 32$ & 56 & $19.29 \pm 0.26^{\mathrm{e}}$ \\
\hline
\end{tabular}

Means of developmental period followed by the same letter are not significantly different (Duncan's Multiple Range test at 5\% level); * Estimated from cycling temperature data.

can be completed by 19 days at $30^{\circ} \mathrm{C}$ and $80 \%$ relative humidity. Temperature limits for the development are $16^{\circ} \mathrm{C}$ and $35^{\circ} \mathrm{C}$ and humidity between $50-90 \%$ which seem to have little effect on the rate of development. Grewal and Atwal (1967) concluded that 25 $30^{\circ} \mathrm{C}$ and $80 \% \mathrm{RH}$ are most favourable for development, survival and reproduction of the Indian strain of $S$. cerealella. The highest population increase of $S$. cerealella occurred at $30^{\circ} \mathrm{C}$. High relative humidity and temperatures higher than $30^{\circ} \mathrm{C}$ are not suitable for development of this pest (Hansen et al. 2004). The wing span was 10-15 mm, body length 5-10 mm with grayish/yellowish, darker spots on forewings. The apex of hind wings was fringed with hairs, which was sharply pointed towards the tips and widely separated so that abdomen is partially visible. Adults mate $24 \mathrm{hrs}$ after emergence. The shape of their abdomen distinguished male and female. In males, the abdomen was thinner, pointed and blackish when viewed from the ventral side whereas in females the abdomen was bulky and long without any blackish colouration.

However, The Angoumois grain moth, Sitotroga cerealella is one of the most serious pests of stored rice (unhusked) at post harvest level. The moth develops through egg, five larval instars, pupa, pre-pupa and adult stages.

\section{References}

Anon. 1981. Statistical Year Book of Bangladesh. Bangladesh Bureau of Statistics. Statistics Division, Ministry of Planning, Government of the People's Republic of Bangladesh, 156 P.

Anon. 2001. Year Book of Statistics of Bangladesh. Bureau of Statistics. Statistics Division, Ministry of Planning, Government of the People's Republic of Bangladesh, 136 P.

Ayertey, J.N. 1975. Egg lying by unmated females of Sititroga cerealella (Lepidoptera: Gelechiidae). J. Stored Prods. Res. 11(3/4):211 -215.

Cogburn, R.R. 1975. Stored rice insect research, The Rice J. 7:78. 
Crombie, A.C. 1943. The development of Angoumois grain moth Sitotroga cerealella Oliv. Nature. 152 (3852):246.

Dhotmal, N.J. and R.B. Dumbre. 1982. Laboratory studies on the bionomics of Angoumois grain moth, Sitotroga cerealella Oliv. on different rice varieties (Lepidoptera: Gelechiidae). Bull. Grain Tech. 20(1):220 -222.

Douglas, W. A. 1941. Field infestation of insects that injure rice in storage. Circ. USDP, No. 602: p. 8.

Fletcher, T.B. and C. C. Ghosh. 1919. Stored grain pest. Proc III entomol. Meetg. Held at Pusa. pp. $712-761$.

Germanov, A. 1982. Development and behavior of larvae of Angoumois grain moth, Sitotroga cerealella Oliv. under conditions of mass rearing. Rasteniev dni Naeuki. 19(5): 87 -95.

Grewal, S. S. and A. S. Atwal. 1967. The influence of temperature and humidity on the development of Sitotroga cerealella Olivier (Lepidoptera: Gelechiidae). J. Res. 6: 353 358 .

Hansen, L. S., S. Henrik and K. Hell. 2004. Life Table Study of Sitotroga cerealella (Lepidoptera: Gelechiidae), a strain from West Africa. J. Econ. Entomol 97 (4): 1484 - 1490.

Hill, D. S. 1990. Pests of stored products and their control. S. K. Jain for CBS Publishers \& Distributors (Pvt.) Ltd. New Delhi, India. pp. 152-153.

Prakash, A., I. C. Pasalu and K.C. Mathur.1981. Plant products in insect pests management of stored grains. Bull. Grain Technol. 19 (3): 213-219.

Prakash, A., I. C. Pasalu and R. Jagadiswar. 1984. The pest status of insects infesting rice stored in Orissa (India). Tropical Stored Prod. Inf. 47, L: 15-20.

Weston, P. A. and P. L. Rattlingourd. 2000. Progeny production by Tribolium castaneum (Coleoptera: Tenebrionidae) and Oryzaephilus surinamensis (Coleoptera: Silvanidae) in maize previously infested by Sitotroga cerealella (Lepidoptera: Gelichiidae). J. econ. Entomol. 93: 533-536. 